\title{
GÊNERO, SEXUALIDADES E DESLOCAMENTOS: NOTAS ETNOGRÁFICAS SOBRE IMIGRANTES E "REFUGIADOS LGBTI" NO NORTE DO BRASIL
}

\section{Gender, sexualities and displacements: ethnographic notes about immigrants and "LGBTI refugees" in the North of Brazil}

\author{
Isadora Lins França* \\ Arthur Fontgaland ${ }^{* *}$
}

\begin{abstract}
Resumo. Neste trabalho, partimos da emergência da categoria de "refugiados LGBTI" nos anos 2000 e de como ela tem operado no Brasil, para em seguida apresentar uma visão de conjunto em torno da literatura sobre o tema. Num segundo momento, tensionamos essa literatura mobilizando notas etnográficas de pesquisas realizadas num abrigo voltado para refugiados reconhecidos como "LGBTI" em Manaus e na Operação Acolhida em Boa Vista e em Pacaraima, na região Norte do Brasil. Além de oferecer uma contribuição desde a perspectiva antropológica para um tema relativamente novo no entrecruzamento entre refúgio, gênero e sexualidade, o artigo visa também contribuir para as pesquisas sobre as recentes migrações venezuelanas.
\end{abstract}

Palavras-chave: sexualidade; gênero; refugiados; "LGBTI"; migrações venezuelanas.

Abstract. This article departures from the emergence of the "LGBTI refugee" category in 2000's and examine the ways by which the category has been operating in Brazil. In a second moment in the article, an overview of the literature related to the theme is presented. This literature is after this tensioned by ethnographic researches carried out in a shelter devoted to "LGBTI refugees" in Manaus and in the middle of the "Operação Acolhida" in Boa Vista and Pacaraima, in the North of Brazil. The article aims to present a contribution, from an anthropological approach, to an issue which is relatively recent in the articulation of asylum, gender and sexuality, as well as collaborate to researches about the equally recent Venezuelan migrations.

Keywords: sexuality; gender; refugges; "LGBTI"; Venezuelan migrations.

\footnotetext{
* Professora do Departamento de Antropologia do IFCH/Unicamp. Campinas - SP, Brasil. E-mail: doralins@unicamp.br. Orcid: 0000-0002-2103-8230.

** Doutorando em Antropologia Social pela USP. São Paulo - SP, Brasil. E-mail: fontgaland@usp.br. Orcid: 0000-0003-2992-7179.
} 


\section{Introdução}

Neste trabalho, partimos do reconhecimento da própria emergência da categoria de "refugiado LGBTI" (Lésbicas, Gays, Bissexuais, Mulheres e Homens Transexuais, Travestis e Intersexo), apresentando num primeiro momento uma visão de conjunto dos dados disponíveis no Brasil e da literatura sobre o tema. Num segundo momento, tensionamos essa literatura a partir de notas etnográficas de pesquisas realizadas no ano de 2019 por Fontgaland e por França, em meio à Operação Acolhida em Boa Vista e em Pacaraima, estado de Roraima, e num abrigo voltado para refugiados reconhecidos como "LGBTI" em Manaus, no Amazonas, respectivamente.

Um aspecto que merece atenção é o alargamento das noções de refúgio: se a categoria "refugiado" emerge no momento histórico do pós-Segunda Guerra como "categoria social específica e problema legal de dimensões globais" (Malkki, 1995, p. 498), o início do nosso século é marcado por seus desdobramentos. Essa tendência revela-se nas diretrizes do ACNUR (Agência da ONU para Refugiados) para a proteção de sujeitos como "LGBTI", "mulheres" e "crianças". Como resultado, no marco dos direitos relacionados ao refúgio, os "LGBTI" têm sido compreendidos como potencial "grupo social específico", passível de obter proteção internacional em contextos nos quais o solicitante apresenta "fundado temor de perseguição em razão da sua orientação sexual e/ou identidade de gênero real ou percebida" (ACNUR, 2012).

É importante enfatizar que entendemos as categorias, "refugiado" e "LGBTI" como construções históricas e situadas. Em termos metodológicos, isso se traduz na recusa a tratar tais categorias como descritivas de uma "essência" ou "experiência compartilhada" (Malkki, 1995). Significa também que no plano das trajetórias e das experiências sociais as distinções entre imigrantes e refugiados podem ser muito mais tênues do que quer o universo dos direitos. No que refere às múltiplas identidades e práticas reconhecidas a partir do amplo guarda-chuva "LGBTI", também é importante lembrar que as fronteiras entre identidades sexuais e de gênero apresentam-se na vida social de forma bastante porosas, como já tem sido explorado pelos estudos de gênero e sexualidade (Foucault, 1982; Butler, 1990). Por esse motivo, "refugiados LGBTI", é uma categoria que sempre aparecerá entre aspas neste artigo, "sob rasura", nas suas versões "destotalizadas e desconstruídas" (Hall, 2000) ${ }^{1}$, indicando que se trata de categoria sob análise, muito mais do que categoria analítica.

1 Nos documentos relacionados ao ACNUR, a categoria mais usada tem sido a de SOGI (Sexual Orientation e Gender Identity) para referir a orientação sexual e identidade de gênero. Optamos pelo uso de "refugiados LGBTI" na sua forma "sob rasura" porque nos interessa justamente a emergência da categoria, seus usos e negociações. Além disso, consideramos que a categoria tem sido utilizada pelos movimentos de imigrantes e refugiados que se identificam como LGBTI, como a pesquisa de França no Brasil e na Espanha vem demonstrando. Cientes da inexistência 


\section{Números sobre "Refúgio LGBTI" no Brasil}

Em 2019, o ACNUR-Brasil lançou um dos poucos levantamentos sobre refúgio com base em orientação sexual e identidade de gênero, o que torna esses números importantes para um panorama geral do que se tem registrado oficialmente no Brasil (ACNUR, 2019). O levantamento contabilizou 369 solicitações de refúgio realizadas no país até 2016, das quais até 2018 52,8\% seguiam pendentes, $10,8 \%$ haviam sido recusadas ou arquivadas e $35,2 \%$ reconhecidas.

Do universo de solicitações registradas neste período, 68,6\% dizem respeito a "homens gays" e "bissexuais" em sua maioria de países de África $(57,3 \%)$ como Nigéria, Gana e Camarões. As solicitações de "mulheres lésbicas" correspondem a 10,3\%, das quais 55,5\% são de países de África, como Camarões, Angola e Gana². O número de "mulheres trans" não chega a $1 \%$ do total, todas de Angola. Cerca de 50 pessoas constam como "sem informação". A maioria das solicitações são de pessoas de países do continente africano (82\%), especialmente da Nigéria, Gana e Camarões, três países em que existem leis de criminalização da homossexualidade, conforme Fontgaland e Verdade (2019). Em menor medida, estão as solicitações de países latino-americanos como Colômbia e Venezuela.

Ainda que os números sejam muito bem-vindos, não devem ser tomados como uma fotografia das mobilidades internacionais de "LGBTI", mas como uma imagem das solicitações registradas pelo CONARE, passíveis de subnotificação. Além disso, os números relacionados aos "refugiados LGBTI" não incluem o recente ingresso de 264 mil venezuelanos no Brasil ${ }^{3}$, que têm sido registrados na sua maioria como solicitantes de refúgio. É justamente pelas lacunas em relação às migrações venezuelanas na articulação com sexualidade e gênero que decidimos explorar este aspecto neste artigo. Antes de passar a esse tema, porém, trataremos brevemente das pesquisas acadêmicas sobre "refugiados LGBTI".

de qualquer categoria não-problemática, optamos pela inteligibilidade da categoria "refugiados LGBTI" e pelo seu potencial de mobilização política.

2 Além de identificados como pertencendo ao amplo guarda-chuva "LGBTI", o ACNUR também considera no levantamento as solicitações de refúgio realizadas por pessoas que não se reconhecem amplamente como "LGBTI", mas são percebidas como tal. Geralmente se trata de ativistas e defensoras dos direitos à diversidade sexual e de gênero.

3 Fonte: ACNUR. Brasil torna-se o país com maior número de refugiados venezuelanos reconhecidos na América Latina. 2020. Disponível em: <https://www.acnur.org/portugues/2020/01/31/ brasil-torna-se-o-pais-com-maior-numero-de-refugiados-venezuelanos-reconhecidos-naamerica-latina/\#: : :text=As\%20autoridades\%20brasileiras\%20estimam\%20que,para\%20o\%20 estado\%20de\%20Roraima>. Acesso em: 28.05.2020. 


\section{Refúgio, sexualidade e gênero: a literatura nas Ciências Sociais}

As articulações entre migração, refúgio, gênero e sexualidade têm suscitado interesse crescente nas Ciências Sociais, dando contorno a um conjunto de pesquisas sobre o tema dos "refugiados LGBTI" na última década. As pesquisas têm chamado a atenção para um sistema de gestão de populações imigrantes/refugiadas que combina dispositivos de detenção e controle com políticas humanitárias discricionárias e restritas (Fassin, 2011). De maneira geral, as pesquisas observam a manutenção de políticas securitárias relacionadas aos deslocamentos e que resultam, no que concerne a "LGBTI", na persistência da perspectiva de comprovação da identidade sexual dos solicitantes. Ainda que por parte de agentes de proteção e nos documentos internacionais seja possível verificar em muitos casos a preocupação com o resguardo da "intimidade" do solicitante, a composição de uma narrativa considerada plausível acaba por supor certa estabilidade em termos da trajetória afetivo-sexual dos sujeitos.

Parte dos trabalhos têm se dedicado, portanto, ao duplo processo de produção da verdade implicado no reconhecimento do "refugiado LGBTI" no âmbito das políticas administrativas do refúgio, considerando que os solicitantes de refúgio com base em orientação sexual e identidade de gênero são interpelados por processos administrativos que, ao final, atestarão sua condição dupla de "refugiado" e de "LGBTI" (Kobelinsky, 2013; Bennett, 2014; Fassin, Salcedo, 2015; Murray, 2017; França, 2017; McNeal, 2019). Nesse terreno, o dispositivo da sexualidade, central na produção da verdade dos sujeitos contemporâneos (Foucault, 1982, 1994, 2008), se articula aos dispositivos de produção de verdade relacionados ao refúgio, resultando na produção de sujeitos reconhecidos pelo Estado e também daqueles que terão seu reconhecimento negado (Facundo, 2017).

As pesquisas também têm produzido informação relevante sobre as experiências vividas por refugiados ou solicitantes de refúgio amplamente reconhecidos como "LGBTI". Merece destaque a precariedade enfrentada por refugiados no país de destino, marcada pela informalidade em termos laborais e pela espera frente aos arrastados processos de reconhecimento. Em relação às precariedades, ainda, é importante notar os efeitos do emaranhado burocrático: são as condições de não-reconhecimento, temporárias ou não, que expõem imigrantes e refugiados a um cotidiano de precariedade que os torna vulneráveis à exploração (Giametta, 2017). Assim, antes de ser uma condição inerente ao "refugiado", a precariedade pode ser melhor entendida como um efeito da gestão das fronteiras nacionais nos processos de deslocamento (Seitz, 2017; Wright, 2018; Hodge, 2019).

É importante mencionar, contudo, que a gestão das precariedades entre imigrantes/refugiados não se limita ao enquadramento jurídico propriamente 
dito: se os documentos são fundamentais para uma vida digna, a regularização da situação migratória por si só não elimina as dificuldades do enfrentamento cotidiano com a pobreza. Raça, gênero e sexualidade seguem operando na produção das precariedades laborais e nas dinâmicas de violência vividas por refugiados reconhecidos como "LGBTI" nas periferias das grandes cidades, ganhando contornos distintos a depender do contexto nacional que se apresenta, como vêm demonstrando as pesquisas (Bhagat, 2017; Zaidan, 2018; França, 2019a; Shakhsari, 2020).

A literatura enfatiza também a dificuldade para o estabelecimento de redes de apoio e de ajuda no país de destino: em muitos casos, as relações de solidariedade com imigrantes do país de origem são dificultadas pelo medo de que se repitam as situações de violência que motivaram o deslocamento inicial. Embora as causas para os deslocamentos de "LGBTI" sejam múltiplas, é muito frequente que tenham relação com a violência de Estado ou com aquela perpetrada por familiares. Dessa forma, as redes de parentesco que convencionalmente atuam em projetos migratórios deixam de operar quando os familiares são os principais agressores (Andrade, 2019; Bhagat, 2020).

A contribuição da literatura tem sido notável ao marcar o lugar das questões que articulam sexualidade e gênero no debate acadêmico sobre migrações e refúgio. Contudo, os contextos etnográficos inicialmente se limitaram bastante à experiência de refugiados nos Estados Unidos, Canadá, Austrália e países da Europa Ocidental. O efeito de conjunto, ainda que involuntário, tende a reforçar a ideia de que países do chamado "Norte Global" são como "destinos naturais" para "refugiados LGBTI", obscurecendo as migrações Sul-Sul que se dão nesse contexto.

Apenas mais recentemente o conjunto de contribuições sobre o tema tem se pluralizado, como atestam os trabalhos produzidos na África do Sul (Bhagat, 2017; Camminga, 2019), na Turquia e no Líbano (Kivilcim, 2017; Myrttinen, Khattab, Maydaa, 2017; Zaidan, 2018; Greatrick, 2019; Shakhsari, 2020), na Sérvia (Badali, 2019) e no México, sobretudo com a mais recente onda de imigrantes vindos de El Salvador, Guatemala e Honduras (Modesto, 2017; Romero, Huerta, 2019; Lucero Rojas, 2019; Zarco Ortiz, Chacon Reynosa, 2020). No Brasil, além da pesquisa realizada por França (França, Oliveira, 2016; França, 2017, 2019), destacam-se as dissertações de mestrado de Vítor Andrade sobre "refugiados e solicitantes de refúgio por motivos de orientação sexual" na cidade de São Paulo (Andrade, 2019), de Cileide Inácio sobre "mulheres negras lésbicas refugiadas" também na mesma cidade (Inácio, 2019) e de Nathália Antonucci Fonseca sobre "mulheres não-cisheterossexuais venezuelanas e solicitantes de refúgio" no Rio de Janeiro (Fonseca, 2020).

Outro viés relevante diz respeito ao perfil dos deslocamentos: a maior parte da bibliografia tem se concentrado nos casos individuais, quando a violência e 
a discriminação em razão de gênero e sexualidade são a principal motivação para o deslocamento. As experiências de sujeitos reconhecidos ou identificados como "LGBTI" em meio a deslocamentos massivos ainda resta bastante lacunar. Tais contextos etnográficos tendem a levar ao reposicionamento do debate sobre elegibilidade e reconhecimento, pois o que está em jogo aqui é o reconhecimento massivo de imigrantes ${ }^{4}$. Consideramos, portanto, que há um espaço importante para avançar no que concerne à pesquisa sobre imigrantes/ refugiados identificados como "LGBTI" em meio a migrações massivas, como são as migrações venezuelanas na região Norte do Brasil.

Nas próximas seções, com o intuito de contribuir para essa discussão, apresentamos uma reflexão com base em notas etnográficas das pesquisas realizadas no ano de 2019 em Manaus e em Boa Vista e Pacaraima por França e Fontgaland, respectivamente. Trata-se de um recorte de pesquisas antropológicas mais amplas realizadas pelos autores sobre o tema do refúgio, gênero e sexualidade. O material reunido é analisado à luz desses contextos mais amplos e é decorrente da pesquisa qualitativa, pautada pela interlocução com os sujeitos de pesquisa ${ }^{5}$.

\section{Pacaraima e Boa Vista: "refugiados e imigrantes LGBTI" nos abrigos da ajuda humanitária}

Para alguns dos agentes humanitários, a gestão migratória concentrada em Roraima tem reforçado em suas ações e projetos a presença e a participação de venezuelanos "identificados como LGBTI". A Operação Acolhida - ForçaTarefa Logística Humanitária para o Estado de Roraima é o modelo de gestão migratória voltado ao atendimento emergencial aos venezuelanos e instalado na cidade de fronteira, Pacaraima, e na capital do estado, Boa Vista. No âmbito da Operação Acolhida o UNFPA e o ACNUR são as principais

4 Neste artigo, nos interessam particularmente as migrações de venezuelanos/as no Norte do país. Em relação aos processos de reconhecimento nesse contexto, Vasconcelos e Santos (2019) recuperam alguns pontos da complexa articulação sobre a necessidade de classificação e categorização das migrações venezuelanas no Norte do Brasil.

5 França vem pesquisando desde 2015 a emergência da categoria "refugiados LGBTI" no mundo institucional e entre os próprios imigrantes e refugiados no Brasil e na Espanha. Fontgaland, em sua pesquisa de doutorado em curso desde 2019 analisa os efeitos de uma governança migratória que oscila entre o humanitarismo e o militarismo. No caso de França, o campo inclui entrevistas formais e informais com refugiados/as e agentes institucionais, além de visitas realizadas ao abrigo e que compreenderam a realização de observação participante, todas as atividades realizadas em janeiro de 2019. Fontgaland pautou-se pela convivência com agentes no campo, bem como pela realização de entrevistas formais e informais, entre 2 a 30 de outubro de 2019. A perspectiva metodológica é a etnográfica, tal como entendida na disciplina antropológica, como a produção de um conhecimento que se dá na relação com os sujeitos e se completa na escrita etnográfica, ou seja, que tem no diálogo com os interlocutores e na compreensão de seus pontos de vista parte fundamental da produção de conhecimento. Neste texto, por isso mesmo, o uso de itálico indica palavras, expressões e falas dos nossos interlocutores. 
agências na região destinadas a realizar ações e projetos voltados para a população "LGBTI" migrante e refugiada em parceria com as ONGs e outras entidades $^{6}$. Ao UNFPA, de modo específico, cabe priorizar o atendimento a pessoas "LGBTI" venezuelanas, além de atuar com outros públicos. A agência é responsável por identificar vulnerabilidades e necessidades de proteção social, por fornecer informações sobre empoderamento e direitos "LGBTI" no Brasil. Mantém também espaços de escuta e acolhimento nos Postos de Interiorização e Triagem (PITRIG) da Operação Acolhida, em Pacaraima e Boa Vista (UNFPA, 2018).

Diferente de Manaus, no estado de Roraima não existem abrigos específicos para imigrantes e refugiados LGBTI. São trezes instalações coletivas voltadas ao abrigamento que compõem a Operação. Onze estão distribuídos por diferentes bairros de Boa Vista e dois estão localizados em Pacaraima. A maioria dos abrigos são gerenciados pelo ACNUR em parceira com o Exército e ONGs. Em março de 2020 cerca de 6.084 pessoas viviam nos abrigos (ACNUR, 2020), que operavam à época acima de suas capacidades.

A recomendação dos organismos internacionais é o abrigamento de refugiados e imigrantes $L G B T I$ junto aos demais venezuelanos. Contudo, essa diretriz não encontra consenso entre os profissionais da ajuda humanitária acessados. A favor do abrigamento misto pesa a ideia de que a convivência plural promove o aprendizado das diferenças. $\mathrm{O}$ argumento contrário reforça que a estratificação social é reproduzida dentro dos abrigos e se expressa cotidianamente em inúmeras formas de violências contra mulheres e pessoas fora dos padrões de gênero e sexualidade. Todos eles defendem as ações específicas destinadas as pessoas identificadas como "LGBTI" e reforçam as intensas disputas travadas com outros agentes da Operação para mantê-las e aprimorá-las.

De modo geral, são muitos os perfis de abrigados em cada instalação. Existem abrigos, por exemplo, que acomodam apenas famílias com filhos, outros estão focados em famílias sem crianças e homens sozinhos. Há abrigo exclusivamente indígena, alguns que comportam no mesmo espaço grupos familiares com filhos, mulheres solteiras, homens solteiros, e "LGBTI", entre outros $^{7}$. Uma agente técnica de uma ONG que havia atuado no abrigamento por cerca de seis meses em 2018 afirma que frequentemente os abrigados não "LGBTI" reclamam de dormir próximos a pessoas identificadas como "LGBTI". Em algumas instalações os venezuelanos LGBTI são acomodados todos juntos e

\footnotetext{
6 As principais ações realizadas por organismos internacionais voltadas à população LGBTI refugiada e imigrante em Roraima, no período que compreende 2018-2019, foram levantadas por Santos (2019).

7 Os diferentes perfis de abrigados por instalação referentes a março de 2020 estão disponíveis em: <https://data2.unhcr.org/ar/documents/download/75317>. Acesso em: 21.04.2020.
} 
possuem horários específicos de banho. Na avaliação dela, "acontecem muito mais conflitos entre a comunidade de abrigados, incluindo a manifestação de LGBTfobia, do que chega aos profissionais, pois violências quando reportadas podem levar à expulsão do abrigo".

Especialmente no início da Operação os protocolos para o acolhimento de "refugiados LGBTI" eram novidade para inúmeros profissionais, como os das Forças Armadas. Muitas diretrizes ainda eram difusas e contavam com certo experimentalismo ao serem aplicadas em determinadas situações. Foi o que deixou a entender um oficial do Exército ao guiar a visita em uma unidade de abrigamento. Na ocasião o militar chega a mencionar que: "à medida que a população LGBT vinha pros abrigos, a gestão teve que testar com quais perfis a convivência seria melhor (...) a solução foi deixá-los com as mulheres solteiras, mas sempre tem que ter negociação" ${ }^{\prime 8}$.

A gestão de proteção nos abrigos parece se aperfeiçoar conforme a heterogeneidade de demandas emerge e enquanto o abrigamento passa a ser mais duradouro do que o planejado inicialmente. São variados os exemplos de trajetórias de pessoas com identidades sexuais e de gênero distintas do padrão cisgênero e heterossexual: há pessoas que se sentem seguras para manifestar sua orientação sexual em público somente após ter certeza que será interiorizado, pois corre nos abrigos o rumor de que "LGBTI" não são prioridade no programa de interiorização. Este caso é mais observado entre homens gays cisgênero. Existem aqueles que se consideram fora das convenções de gênero e sexualidade hegemônica e também não se reconhecem como "LGBTI". Já outras pessoas vieram para o Brasil tanto para buscar emprego, quanto para realizar os procedimentos necessários à transição de gênero longe da família e seguem enviando alguns recursos para os pais ${ }^{9}$. Receiam, entretanto, comentar com eles sobre a transição e sobre viver em abrigos.

Em conversas com profissionais do UNFPA eles ressaltaram que a atenção à população $L G B T I$ abrigada garante, por exemplo, o direito ao uso de nome social nas carteirinhas de identificação dos abrigos e o acesso a espaços seguros nos abrigos e fora deles, com endereço secreto. É incentivada também a formação de coletivos "LGBTI" que promovem atividades culturais e políticas, como já vem ocorrendo em alguns abrigos da capital, como Rondon 3 e Latife Salomão. Existem ainda eventos e rodas de conscientização sobre diversidade sexual e de gênero para o público abrigado não "LGBTI".

Frequentemente alguns abrigados, não apenas os identificados como "LGBTI", deixam as instalações da Operação Acolhida por dificuldades de

8 Entrevista realizada por Fontgaland em 23 de outubro de 2018.

9 Sobre a intensa mobilidade trans por regiões de fronteira e as variações de autoidentificação, desejos e transformações corporais realizadas ao longo do processo ver Nascimento (2016). 
se adaptar a determinadas regras. Quando evadem, muitos dos abrigados se dirigem às inúmeras ocupações de venezuelanos que existem na cidade ou passam a viver em situação de rua. Contudo, constantemente foi relatado sobre o perigo de viver na rua, sobretudo sendo mulher e/ou "LGBTI". Este tipo de situação não é exclusividade de Boa Vista. Mas algumas regiões da capital roraimense (inclusive o em torno de alguns abrigos específicos) são especialmente evitadas por essa população devido a episódios de estupros e agressão física cometidas contra as pessoas identificadas como homens gays e transexuais venezuelanas.

Se a presença de refugiados e imigrantes em situação de rua em Boa Vista - e entre eles, a população reconhecida como "LGBTI" - foi atestada durante a pesquisa de Fontgaland, vale mencionar que ela antecedeu a instalação dos abrigos. Segundo o relato da diretora de uma ONG cristã local que atuava com refugiados e imigrantes entre 2016 e 2017, antes mesmo do estabelecimento da Operação Acolhida, era possível se deparar com uma heterogeneidade de pessoas em situação de rua, incluindo venezuelanos lidos como "LGBTI". Além disso, já era notada a situação de maior precariedade das pessoas identificadas como trans: "conseguir emprego era difícil pra qualquer um, é verdade, mas as trans que a gente conhecia e ajudava enfrentavam muitas dificuldades devido ao estigma. Não conseguiam emprego por ser venezuelana e trans. Eram vistas como perigosas, prostitutas, doentes ou ignoradas pelos outros venezuelanos por serem trans ${ }^{\prime 10}$. A ativista também menciona que nesse período era corriqueiro as trans venezuelanas apresentarem marcas de agressões ou mencionarem as mortes de outras colegas. Ela chega a lembrar de uma delas que em 2017 foi brutalmente assassinada a facadas no centro de Boa Vista por um cliente que se recusou a pagar o valor do programa.

Alguns interlocutores de Fontgaland atuantes na OIM e no UNFPA no período da pesquisa também identificavam que o desemprego e a violência eram as principais precariedades enfrentadas especificamente por venezuelanas reconhecidas como trans e que se encontravam em situação de rua em Boa Vista. Apesar da situação de precariedade vivida, relataram, contudo, que um pequeno grupo de garotas trans venezuelanas que vivia há meses em uma praça da capital teve papel importante para a efetivação das atividades da Operação Acolhida. Sobretudo, elas contribuíram para mobilizar parte da comunidade venezuelana em situação de rua que seria direcionada para os abrigos recém construídos pelas Forças Armadas.

Franci é uma das jovens trans consideradas pelos interlocutores de Fontgaland como liderança venezuelana que vivia na Praça Simon Bolívar

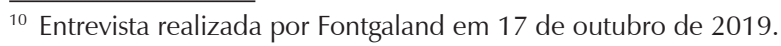


antes de ser interiorizada para o Rio de Janeiro. Em artigo ${ }^{11}$ publicado sobre interiorização de transexuais venezuelanas, ela conta que a perda da qualidade de vida em razão da crise econômica de seu país motivou a migração: "Eu tinha minha casa na Venezuela, meu carro, tinha minha vida profissional, sou engenheira industrial. Mas quis sair de lá e peguei dinheiro para ir até a fronteira com o Brasil". Franci ressalta as dificuldades de encontrar trabalho em Roraima, mesmo tendo qualificação profissional. O artigo destaca que em Boa Vista as trans eram constantemente vistas como prostitutas, o que levava a frequentes conflitos com travestis brasileiras.

Quando perguntados se havia mais informações sobre os processos que constituíram essas transexuais venezuelanas como lideranças, os profissionais das agências humanitárias infelizmente não souberam precisar, mas reforçaram a importância da contribuição delas para que os organismos internacionais dessem seguimento a ações para a proteção de imigrantes e refugiados LGBTI. A aliança entre essas venezuelanas e as agências de ajuda humanitária, sugerem alguns dos interlocutores, pode ter levado à relativamente rápida interiorização deste grupo de jovens trans para outra região do país. Vale observar que os profissionais da ação humanitária consultados reconhecem o quanto as pessoas venezuelanas abrigadas identificadas como "LGBTI" são diversas entre si. Tal diversidade implica em processos de mobilidade muitas vezes distintos e em exposição a violências e abusos baseados em expressões de gênero e orientação sexual. Nesse sentido, as pessoas trans são entendidas como mais vulneráveis, assim como há certa identificação de situações excludentes nos abrigos e protocolos constantemente negociados para contorná-los.

Ao mesmo tempo que há o reconhecimento das diferenças observadas nas trajetórias e situações específicas entre abrigados lidos como "LGBTI", os profissionais da ajuda humanitária também operam com categorias e práticas voltadas à gestão populacional. Eles mesmos percebem e produzem constantemente uma noção de população LGBTI. A organização dos abrigados em perfis, entre eles o perfil LGBTI, por exemplo, acaba tendo um desejado efeito estabilizador para fins de gestão dos refugiados e imigrantes venezuelanos. O mesmo efeito tende a operar no uso das categorias população LGBTI abrigada, LGBTI venezuelanos ou refugiados $L G B T I$ mobilizadas pelos gestores e técnicos dos abrigos. Ainda que haja estabilização, a realidade apresenta identificações sexuais e de gênero menos estáveis e categóricas, cujas relacionalidades também são afetadas pelo contexto excepcional no

11 Fonte: < https://g1.globo.com/rj/rio-de-janeiro/noticia/2018/08/29/apos-fugir-da-venezuela-tra nsexuaistentam-recomecar-vida-no-rio-e-relatam-preconceito-e-agressoes.ghtml>. Acesso em: 20.04.2020. 
qual estes sujeitos estão inseridos. Essa dinâmica também foi observada por França em Manaus, assunto da próxima seção deste artigo.

\section{Manaus: o primeiro abrigo voltado para "refugiados LGBTI" no Brasil}

O primeiro abrigo do Brasil voltado para refugiados $L G B T I$ foi inaugurado no final de 2018. A "Morada"12 é um pequeno abrigo que conta com capacidade para pelo menos oito pessoas, que podem residir no local até 45 dias, com vistas a estabelecer-se na cidade e buscar alternativas de geração de renda que lhes permitam alugar um espaço próprio. Nos primeiros três meses após a saída do abrigo, é oferecido a essas pessoas um auxílio para pagamento do aluguel.

A impressão ao chegar ao abrigo, numa distância a pé de cerca de 15 minutos desde um terminal rodoviário urbano central em Manaus, é a de que se trata de uma das pequenas casas térreas que povoam a paisagem da cidade. O projeto foi financiado em parte pela União Europeia, que possibilitou ao ACNUR a doação de mobiliário, uma máquina de lavar roupas e uma televisão. A outra parte dos recursos veio da mobilização do movimento LGBTI+ manauara: doações online, a doação do cachê de uma artista da cidade e uma feijoada reuniram o valor necessário para o pagamento do aluguel da casa por um ano. A "Morada" já existia quando do início da parceria com o ACNUR em Manaus: assim como outros projetos similares existentes no país, era um abrigo destinado a "LGBTI+" expulsos da casa da família.

Segundo entrevista com o chefe do escritório do ACNUR em Manaus ${ }^{13}$, a parceria integrou a estratégia da organização de descentralizar e capilarizar a rede de atendimento a partir dos serviços e equipamentos já existentes na cidade, apoiando essas iniciativas e as capacitando para o atendimento de refugiados. A demanda chegava pela presença clara de pessoas reconhecidas como "LGBTI" em meio à migração venezuelana e pela estratégia de promover respostas variadas para públicos específicos, já existindo ações para mulheres e crianças e adolescentes. Essas eram populações consideradas capazes de apresentar questões classificadas pela operação humanitária como de média e alta complexidade. A ideia de criar um espaço seguro para "LGBTI" inspirava-se em iniciativas no México e em outros países ${ }^{14}$.

\footnotetext{
12 Neste artigo, optamos por chamar essa iniciativa, resultado da parceria entre ACNUR e uma ONG local, de "Morada" simplesmente.

${ }^{13}$ Entrevista realizada por França em 29 de janeiro de 2019.

${ }^{14}$ Segundo publicação da ONU, um "Espaço Seguro é um tipo de espaço físico ou móvel, onde grupos ou indivíduos podem se sentir "seguros", construir redes sociais, se expressar ou passar o tempo, enquanto acessam serviços de proteção e assistência" [tradução livre] (ACNUR, 2018, p. 8).
} 
No caso do encaminhamento para a "Morada", a equipe do ACNUR era responsável por consultar pessoas em outros abrigos sobre a possibilidade de realocação. Em alguns casos, a oferta era recusada, pois já havia rede de amizade e apoio constituída nos abrigos originais. Em outros casos, a oferta era bem-vinda diante da discriminação e violência enfrentada nos abrigos regulares pelos "LGBTI", que muitas vezes ofereciam risco às pessoas assim identificadas, na ausência de supervisão permanente. Os relatos de discriminação e violência contra "LGBTI" não eram incomuns, tanto que um dos primeiros casais residentes na "Morada" era composto por duas mulheres que solicitaram a realocação porque sentiam-se desconfortáveis no abrigo em que estavam originalmente, sendo hostilizadas e tratadas como "mau exemplo" pelos demais.

No que diz respeito à violência sofrida nos abrigos e durante o próprio deslocamento, é corrente entre os agentes envolvidos com o processo de interiorização em Manaus a percepção de que os "LGBTI" encontram-se mais expostos à violência, estando as mulheres trans particularmente expostas a situações de risco. Um agente do ACNUR relatou a França ${ }^{15}$, por exemplo, o caso de uma mulher trans que em meio à sua jornada migratória havia sido cooptada para trabalhar numa fazenda e sofrido violência sexual. Segundo o entrevistado, o abrigo específico para LGBTI pode funcionar aqui como opção de espaço mais seguro nesses casos tidos como de alta complexidade, marcados pela violência sofrida nos deslocamentos realizados, de modo a evitar que esses imigrantes sejam revitimizados ${ }^{16}$.

As primeiras refugiadas abrigadas na "Morada" foram seis mulheres cis venezuelanas, entre dois casais e duas mulheres solteiras. Quando da realização da pesquisa em Manaus, elas já haviam deixado a "Morada" e recebiam auxílio para o aluguel. Apesar da trajetória profissional em seu país, todas batalhavam diretamente nos semáforos de Manaus vendendo água, situação que jamais haviam imaginado encontrar: "Somos 4 aqui e nenhuma conseguiu emprego. Nenhuma. E entregando currículo. Caminhamos, no dia que não trabalhamos saímos para entregar currículos. Nada. Ninguém"1717. Entre esse grupo de mulheres, havia um casal que vivera na Praça Simón Bolívar por

\footnotetext{
15 Ibidem, nota 13.

${ }^{16}$ Em termos das violências sofridas em meio aos processos de deslocamento, a situação não é muito distante daquelas que foram relatadas a França durante pesquisa na Espanha em 2016 e 2017, em que as entidades humanitárias relatavam a existência de situações conflituosas envolvendo "LGBTI" em abrigos.A opção por espaços específicos era sempre pesada em relação a cada situação, persistindo a ideia de que a convivência com a diversidade era positiva para a integração. No caso de violência nos abrigos, a opção comumente variava entre transferir "LGBTI" para abrigos menores formados por outros "LGBTI" ou por famílias ou mulheres vistas como menos propensas a atos de violência e intimidação.

17 Entrevista em grupo realizada por França em 29 de janeiro de 2019.
} 
três meses, logo da chegada a Boa Vista, experiência descrita à pesquisadora como profundamente perturbadora: "fora do tempo, sem relógio, sem celular, como uma indigente" ${ }^{\prime 18}$. De maneira similar a mulheres trans, as mulheres identificadas como lésbicas relataram a França o medo constante da violência sexual nas ruas de Boa Vista, tendo de se deslocar grandes distâncias em horários pouco movimentados para realizar sua higiene pessoal em banheiros públicos.

A situação de precariedade e o risco da violência raramente eram compartilhados com os familiares na Venezuela, que seguiam na expectativa do envio de ajuda financeira por parte das imigrantes. Cabe ressaltar aqui que nesses casos as relações com a família na Venezuela atravessavam a fronteira, em laços que não eram apenas econômicos: as expectativas de ajuda da família eram sentidas como uma obrigatoriedade em certo sentido moral. Vale dizer também que, embora as relações entre ajuda e reconhecimento sejam usualmente complicadas no caso de imigrantes, no que diz respeito a "LGBTI" elas podem ser particularmente difíceis, já que muitas vezes atravessadas por experiências familiares de violência e de não reconhecimento. Neste caso, a própria "aceitação" da sexualidade ou identidade de gênero pelos familiares é negociada a partir do sucesso da empreitada migratória, sucesso este capaz de compensar a desvalorização desses sujeitos em termos de gênero e sexualidade por meio da sua ascensão social e das possibilidades de "ajuda" que ela traz.

Embora normalmente ocultadas da família de origem, a experiência da vida nas ruas e as situações de exploração no deslocamento para o Brasil eram comuns também aos que ainda residiam na "Morada". Quando França visitou a casa, em janeiro de 2019, residiam ali duas mulheres trans, o namorado de uma delas, e um homem gay, todos venezuelanos ${ }^{19}$. Além disso, havia também um casal de mulheres cubanas. Exceto pelo rapaz venezuelano, que conseguira um emprego como costureiro, todas as mulheres trabalhavam informalmente nos semáforos. O homem gay com quem França conversou tivera de acampar na rodoviária de Manaus junto com um grupo de venezuelanos, onde foi localizado pela equipe do ACNUR e conduzido ao abrigo. Naquele momento, a rodoviária de Manaus era ocupada por centenas de venezuelanos que, tendo chegado à cidade por ali, não tinham para onde ir. De certo modo, a liderança que o rapaz exercia no grupo do qual fazia parte na rodoviária e sua identificação como gay atuaram positivamente para que ele conseguisse rapidamente uma vaga na "Morada", quando outros abrigos eram inacessíveis.

\footnotetext{
${ }^{18}$ Ibidem.

${ }^{19}$ As histórias e falas dos interlocutores da "Morada" aqui mobilizadas são decorrentes de observação participante e de conversas informais, por isso não há indicação de entrevistas formais referentes a elas.
} 
O casal de cubanas também havia chegado a Manaus pela rodoviária, num percurso comum aos cubanos, que inclui passar pelas Guianas e atravessar a fronteira para Roraima ${ }^{20}$. Parte desse contingente chega ao Brasil por meio de coiotes, como aconteceu com Rosa e Selena ${ }^{21}$, que pagaram um coiote para a realização da travessia até o Uruguai ${ }^{22}$. Após terem-Ihe entregue quase todo seu dinheiro, decorrente da venda de uma casa em Cuba, foram abandonadas em Boa Vista. No país, Rosa deixara suas duas filhas em busca de uma vida melhor, com o intuito de posteriormente trazê-las para viver consigo. Suas publicações nas redes sociais eram repletas de mensagens de saudades das filhas e da reiteração de que agiu como mãe, na intenção de dar a elas um futuro melhor. As motivações do casal de mulheres para o deslocamento oscilavam entre o preconceito sofrido no país e a necessidade de melhorar sua situação econômica. Assim, Rosa contava que "em Cuba há trabalho, mas o que não há é dinheiro" e Selena emendava que "em Cuba não podia andar tranquila na rua, era ofendida", relatando que as filhas de Rosa frequentemente sofriam humilhações na escola por conta da relação entre as duas. Selena, com uma performance corporal mais masculina, queixava-se muito do preconceito em Cuba: "as políticas LGBT só servem para Havana. No interior, há muito preconceito. Se você é ameaçada e vai à polícia, te chamam de louca".

O preconceito, comum ao relato de imigrantes e refugiados identificados como "LGBTI", também atravessa a história de Martina, que migrara para o Brasil para ajudar a mãe, recentemente falecida. Em Boa Vista, conheceu o namorado Gabriel, que a seguiu até Manaus quando lhe ofereceram a interiorização. Ambos tinham cerca de 20 anos quando da realização da pesquisa. A história de Martina havia sido marcada por uma intensa mobilidade comum às pessoas trans: tendo sido rejeitada pela mãe aos 15 anos, mudou-se para uma cidade do garimpo na Venezuela e ali realizou sua transição de gênero, voltando transformada para a casa da mãe, depois de alguns meses, de onde novamente sairia após alguns anos em direção ao Brasil. A aceitação veio do reconhecimento de que a filha trans era a que mais cuidava da mãe. Das três irmãs, Martina perdeu o contato com duas, uma é trabalhadora do sexo nas Guianas e a outra segue na Venezuela. A possibilidade de Martina

${ }^{20}$ Segundo os últimos números divulgados pelo CONARE, referentes a 2018, naquele ano 2.749 cubanos solicitaram refúgio no país. Embora o número seja muito menor que o número de venezuelanos (61.681) e mesmo de haitianos (7.030), Cuba é o terceiro país com maior número de solicitações, registrando um crescimento de 369 solicitações em 2015 para as 2.749 em 2018. Fonte: BRASIL. Refúgio em Números 4a Edição. Disponível em: <https://www.acnur.org/ portugues/wp-content/uploads/2019/07/Refugio-em-nu\%CC\%81 meros_versa\%CC\%83o-23de-julho-002.pdf>. Acesso em: 25.04.2020.

${ }^{21}$ Assim como o nome do abrigo foi substituído por um nome fictício, os nomes das interlocutoras de França foram todos substituídos por outros, com o objetivo de resguardar as identidades das participantes da pesquisa.

22 Sobre tráfico de imigrantes e gênero, ver Assis (2008). 
conhecer a família de Gabriel era um ponto de tensão entre os dois, pelo receio de Martina em não ser aceita.

Quando a pesquisadora perguntou a Gabriel como ele se identificava em termos da sua sexualidade, ele devolveu-lhe a pergunta: "bom, hetero, mas agora como estou namorando com Martina acho que bissexual, né?". Como as mulheres cubanas e as demais interlocutoras da pesquisa, Gabriel só conhecera a categoria "LGBT" uma vez no Brasil ${ }^{23}$, em meio ao processo migratório. Assim, se no plano das políticas humanitárias a noção de "população LGBTI" é acionada para dar vazão às políticas de gestão dessas populações, no plano dos sujeitos revela-se a negociação dessas categorias, contrariando certa tendência ao seu engessamento e ao mesmo tempo evidenciando como as políticas de gestão das migrações fazem circular novas formas de entendimento sobre sexualidade e gênero entre as populações implicadas.

\section{Considerações Finais}

Como vimos, a concentração de imigrantes venezuelanos na região Norte do país levou à emergência de uma governança migratória específica voltada à documentação, abrigamento e interiorização populacional. Dentre as práticas de ordenamento e gestão adotadas por esse modelo está a visibilidade dada a "refugiados LGBTI" identificados nesse contingente migratório. Tais práticas têm sido centrais para construir alternativas de proteção a esses sujeitos, ao mesmo tempo em que atuam como uma força de estabilização dessas categorias, em torno das quais políticas públicas são formuladas e públicos-alvo são identificados. Entretanto, quando colocadas em ação, essas categorias são agenciadas pelas pessoas, que se esforçam por navegar entre elas, alargando seus limites. Essa é uma dinâmica que faz parte da emergência da categoria de "refugiados LGBTI" no universo dos direitos relacionados ao refúgio desde os anos 2000 (França, 2017).

É por esse motivo que tomamos a categoria de "refugiados LGBTI" sob rasura, como um mote que nos permitiu neste artigo explorar situações vividas por mulheres "lésbicas" e "mulheres trans" como particularmente expostas a situações de violência e de exploração durante sua jornada, frequentemente motivada pela soma entre o preconceito em seus países de origem e a busca por melhores condições de vida. Às situações de violência e exploração, soma-se ainda a dificuldade de conseguir um trabalho digno no país,

\footnotetext{
${ }^{23}$ Em alguns momentos, a curiosidade dos interlocutores sobre as convenções brasileiras de gênero e sexualidade transformava-se em perguntas à pesquisadora: Gabriel seria hetero ou bissexual? Como funcionam os casais de mulheres em que ambas têm uma expressão de gênero parecida? Por que há tantos nomes para travesti no Brasil? Assim, os deslocamentos espaciais proporcionam também deslocamentos em termos de convenções de gênero e de sexualidade proporcionados pelo contraste sobre as convenções vigentes nos diferentes contextos nacionais.
} 
resultando em situações de precariedade laboral. De Boa Vista a Manaus, os trabalhos desempenhados são exaustivos, envolvem longas jornadas sob sol causticante e a humilhação do preconceito contra imigrantes. No caso das "mulheres trans", o trabalho sexual segue ainda como uma das únicas possibilidades de geração de renda.

Nossas pesquisas reforçam a importância de se considerar a diversidade interna ao acrônimo "LGBTI" quando tratamos de refúgio e imigração. Essa perspectiva é também resultado da nossa interlocução em campo: no decorrer das pesquisas, as mulheres, trans e cis, têm surgido como nossas principais interlocutoras ou referências. Isso reforça sua presença importante no tema, muitas vezes obscurecida pelas experiências mais públicas relacionadas às homossexualidades masculinas.

Os aspectos aqui descritos dizem respeito aos temas que emergiram da confrontação entre nossas pesquisas, os dados disponibilizados sobre refúgio e "LGBTI" pelo ACNUR e o conjunto de trabalhos voltados para "refugiados LGBTI" nas Ciências Sociais, que apresentamos brevemente neste artigo. Esperamos dessa forma reforçar a importância de se levar em conta as migrações da América Latina e Caribe nas pesquisas sobre o tema no Brasil. Não pretendemos aqui esgotar o assunto, mas antes apontar espaços onde há ainda muito a avançar, na medida em que o imbricamento entre refúgio e diversidade sexual e de gênero consolida-se no universo institucional e acadêmico. Por fim, tudo isso torna-se tão mais relevante à medida em que se intensificam os deslocamentos humanos num mundo de fronteiras crescentemente vigiadas, em que gênero e sexualidade seguem sendo tanto terrenos de violência como dimensões para a agência daqueles que desafiam a norma.

\section{Referências bibliográficas}

ACNUR. Relatório Mensal. Roraima março de 2020. Roraima, 2020. Disponível em: <https://data2.unhcr.org/ar/documents/download/75317>. Acesso em: 10.04.2020.

ACNUR. Perfil das Solicitações de Refúgio relacionadas à Orientação Sexual e à Identidade de Gênero. 2019. Disponível em: <https://www.acnur.org/portugues/ refugiolgbti/>. Acesso em: 25.03.2020.

ACNUR. The Regional Safe Spaces Network in the Americas: lessons learned and toolkit. 2018. Disponível em: <https://www.acnur.org/5c05b97d4.pdf\%20 acesso\%2025\%20abr\%202020 >. Acesso em: 24.04.2020.

ACNUR. Diretrizes sobre Proteção Internacional n. 09 - Solicitações de Refúgio baseadas na Orientação Sexual e/ou Identidade de Gênero no contexto do Artigo 1A(2) da Convenção de 1951 e/ou Protocolo de 1967 relativo ao Estatuto dos Refugiados. 2012. Disponível em: <https://www.acnur.org/fileadmin/ Documentos/BDL/2014/9748.pdf>. Acesso em: 25.04.2020. 
ANDRADE, Vitor Lopes. Refúgio por motivos de orientação sexual: um estudo antropológico na cidade de São Paulo. Florianópolis: Editora UFSC, 2019.

ASSIS, Gláucia de Oliveira. A fronteira México-Estados Unidos: entre o sonho e o pesadelo - as experiências de e/imigrantes em viagens não-autorizadas no mundo global. Cadernos Pagu, Campinas, n. 31, p. 219-250, 2008.

BADALI, Joel J. Migrants in the closet: LGBT migrants, homonationalism, and the right to refuge in Serbia. Journal of Gay \& Lesbian Social Services, v. 31, n. 1, p. 89-119, 2019.

BHAGAT, Ali. Forced (queer) migration and everyday violence: The geographies of life, death, and access in Cape Town. Geoforum, v. 89, p. 155-163, 2017.

BHAGAT, Ali. Queer necropolitics of forced migration: cyclical violence in the African context. Sexualities, v. 23, n. 3, p. 361-375, 2020.

BRASIL. Refúgio em números. 2020. Disponível in: <https://www.acnur.org/ portugues/wp-content/uploads/2019/07/Refugio-em-nu\%CC\%81 meros versa\%CC\%83o-23-de-julho-002.pdf> Acesso em: 19. 03. 2020.

BENNETT, Claire Maire. Sexuality and the Asylum Process: The Perspectives of Lesbians Seeking Asylum in the UK. (Tese de doutorado). University of Sussex, School of Education and Social Work, Sussex, 2014.

BUTLER, Judith. Problemas de gênero: feminismo e subversão da identidade. Rio de Janeiro: Civilização Brasileira, 2003.

CAMMINGA, B. Transgender Refugees and the Imagined South Africa: Bodies Over Borders and Borders Over Bodies. Palgrave Macmillan, 2019.

FACUNDO, Ángela. Exxodos, refúgios e exílios: colombianos no sul e sudeste do Brasil. Rio de Janeiro: Papeis Selvagens, 2017.

FOUCAULT, Michel. História da sexualidade I: a vontade de saber. Rio de Janeiro: Graal, 1982.

FOUCAULT, Michel. Dits et écrits, 1954-1988. Paris: Editions Gallimard, 1994.

FOUCAULT, Michel. Microfísica do poder. 25. ed. Rio de Janeiro: Graal, 2008.

FASSIN, Didier. Policing Borders, Producing Boundaries. The Governmentality of Immigration in Dark Times. Annu. Rev. Anthropol., v. 40, p. 213-26, 2011.

FASSIN, Eric; SALCEDO, Manuela. Becoming Gay? Immigration Policies and the Truth of Sexual Identity. Archives of Sexual Behavior, v. 44, n. 5, p. 1117-1125, 2015.

FONSECA, Nathália. Entrecruzamentos entre migração, gênero e sexualidade: experiências de vida de mulheres não-cisheterossexuais venezuelanas e solicitantes de refúgio (Dissertação de mestrado). Programa de Pós-Graduação em Antropologia. Universidade Federal Fluminense, Niterói, 2020.

FONTGALAND, Arthur; VERDADE, Marcela. O que os dados do ACNUR apontam sobre as solicitações de refúgio de pessoas LGBTI no Brasil? MigraMundo, 2019. Disponível em: <https://www.migramundo.com/o-que-os-dados-do-acnurapontam-sobre-as-solicitacoes-de-refugio-de-pessoas-lgbti-no-brasil/>. Acesso em: 03.04.2020. 
FRANÇA, Isadora L.; OLIVEIRA, Maurício. "Refugiados LGBTI": gênero e sexualidade na articulação com refúgio no contexto internacional de direitos. Travessia, v. 29, n. 79, p. 33-50, 2016.

FRANÇA, Isadora L. "Refugiados LGBTI": direitos e narrativas entrecruzando gênero, sexualidade e violência. Cad. Pagu, Campinas, n. 50, e17506, 2017.

FRANÇA, Isadora L. "LGBTI Refugees": Rights and Narratives Interlinking Gender, Sexuality and Violence. Cad. Pagu, Campinas, n. 50, e17506, 2017 a.

FRANÇA, Isadora L. Gênero e sexualidade: ascensão conservadora e fantasias masculinas de poder no Brasil. Margem Esquerda, v. 1, p. 45-52, 2019.

FRANÇA, Isadora L. "LGBTI Refugees": narratives, precarities and mobilities. In: XXXVII Congresso da LASA - Latin American Studies Association, Boston, 24 a 27 de maio de 2019a. Mimeo.

GIAMETTA, Calogero. The sexual politics of asylum: sexual orientation and gender identity in the UK asylum System. New York/London: Routledge, 2017.

GREATRICK, Aydan. "Coaching" queer hospitality and the categorical imperative of LGBTQ asylum seeking in Lebanon and Turkey. Migration and Society: Advances in Research, v. 2, n. 1, p. 98-106, 2019.

HALL, Stuart. Quem precisa de identidade? In: SILVA, Tomaz Tadeu da. Identidade e diferença: a perspectiva dos estudos culturais. Petrópolis: Vozes, 2000.

HODGE, Edwin. Making Precarious: the construction of precarity in refugee and migrant discourse. Borders in Globalization Review, v. 1, n. 1, p. 83-90, 2019.

INÁCIO, Cleide Luz Soares. Guerreiras afro-atlânticas: mulheres refugiadas em busca de sua outra no Brasil. (Dissertação de mestrado). Universidade Federal de São Carlos, Programa de Pós Graduação em Educação, Sorocaba, 2019.

JANSEN, Sabine; SPIJKERBOER, Thomas. Fleeing Homophobia, Asylum Claims Related to Sexual Orientation and Gender Identity in Europe. Amsterdam: Vrije Universiteit Amsterdam, 2011.

KIVILCIM, Zeynep. Lesbian, Gay, Bisexual and Transsexual (LGBT) Syrian Refugees in Turkey. In: FREEDMAN, Jane; KIVILCIM, Zeynep; BAKLACIOGLU, Nurcan (eds.). A Gendered Approach to the Syrian Refugee Crisis. New York: Routledge, 2017, p. 26-41.

KOBELINSKY, Carolina. Ver o no ver al refugiado gay: la evaluación de las solicitudes de asilo (por motivos sexuales) en Francia. Temas de antropología y migración, v. 4, p. 13-29, 2013.

LUCERO ROJAS, Miguel. Desplazamiento forzado y refugio: politización de resistencias de mujeres trans centroamericanas en México. (Tesis de doctorado). Colégio de la Frontera Norte, Tijuana, 2019.

MALKKI, Lisa H. Refugees and Exile: From 'Refugee Studies' to the National Order of Things. Annual Review of Anthropology, v. 24, n. 1, p. 493-523, 1995.

MODESTO, Macarena F. W. Sentir en movimiento: emociones de mujeres centro-americanas em tránsito por Tapachula. (Tesis de maestría). Centro de 
Investigaciones y Estudios Superiores en Antropología Social do México, Ciudad de México, 2017.

MYRTTINEN, Henri; KHATTAB, Lana; MAYDAA, Charbel. 'Trust no one, beware of everyone' - vulnerabilities of LGBTI refugees in Lebanon. In: FREEDMAN, Jane; KIVILCIM, Zeynep; BAKLACIOGLU, Nurcan (orgs.). A Gendered Approach to the Syrian Refugee Crisis. New York: Routledge, p. 61-76, 2017.

MCNEAL, Keith. Confessions of an ambivalent country expert: Queer refugeeism in the UK the political economy (im)mobility in and on Trinidad and Tobago. Anthropological Theory, v. 19, n. 1, p. 191-215, 2019.

MURRAY, David A. B. Real queer? Sexual orientation and gender identity refugees in the Canadian refugee apparatus. Londres/Nova York: Roman \& Littlefield International, 2016.

NASCIMENTO, Silvana de Souza. Cidades trans: uma etnografia multi-situada nas fronteiras da antropologia urbana. In: $40^{\circ}$ Encontro Anual da Anpocs. Caxambú, 24 a 28 de outubro de 2016.

ROMERO, Maria Paula; HUERTA Sofía Cardona. Seeking Protection as a Transgender Refugee Woman: From Honduras and El Salvador to Mexico. In: GULER, Arzu; SHEVTSOVA, Maryna; VENTURI, Denise (orgs.). LGBTI Asylum Seekers and Refugees from a Legal and Political Perspective. Springer, p. 251-274, 2019.

SANTOS, Miguel A. M. A atuação das organizações internacionais em Roraima no acolhimento aos migrantes e refugiados LGBTI da Venezuela. (Trabalho de Conclusão de Curso). Universidade Federal e Roraima, Centro de Ciências Humanas, Boa Vista, 2019.

SEITZ, David K. Limbo life in Canada's waiting room: asylum seeker as queer subject. Environment and Planning D: Society and Space, v. 35, n. 3, p. 438-456, 2017.

SHAKHSARI, Sima. The queer time of death: temporality, geopolitics, and refugee rights. Sexualities, v. 17, n. 8, p. 998-1015, 2014.

SPIJKERBOER, Thomas. Fleeing Homophobia: Sexual Orientation, Gender Identity and Asylum. 1. ed. United Kingdom: Routledge, 2013.

UNFPA. UNFPA orienta migrantes e refugiados sobre como acessar as políticas públicas de saúde e proteção social em Roraima. 2018. Disponível em: $<$ https://brazil.unfpa.org/pt-br/news/unfpa-orienta-migrantes-e-refugiadossobre-como-acessar-pol\%C3\%ADticas-p\%C3\%BAblicas-de-sa\%C3\%BAde-eprote $\%$ C3\%A7\%C3\%A3o > . Acesso em: 12.04.2020.

VASCONCELOS, lana; SANTOS, Sando. Refugiados em Roraima? Instituições, papéis e a competição pelas categorias. In: BAENINGER, Rosana; SILVA JAROCHINSKI, João Carlos (orgs.). Migrações Venezuelanas. Campinas, SP: Nepo/Unicamp, 2018, p. 250-258.

WRIGHT, Cynthia. Proliferating borders and precarious queers: migrant justice organising beyond LGBT inclusion. Int. J. Migration and Border Studies, v. 4, n. 1/2, 2018. 
ZAIDAN, Mahdi. We live in shadows: identity, precarity, and activism among LGBT Refugees in Beirut and Athens. (Dissertação de mestrado em estudos árabes). Georgetown University, Graduate School of Arts \& Sciences, 2018.

ZARCO ORTIZ, Ernesto A.; CHACÓN REYNOSA, Karla J. Dispositivos de seguridad y sexualidad en la frontera sur de México: biopolíticas en mujeres transgénero centroamericanas. Tabula Rasa, n. 33, p. 137-163, 2020. 